\title{
PESQUISA EM ONTOPSICOLOGIA ${ }^{1}$
}

\author{
Prof. Dr. Alécio Vidor ${ }^{2}$
}

\begin{abstract}
Resumo: O texto aborda a pesquisa ontopsicológica, no qual afirma que todo o processo de pesquisa para confirmar-se como ciência precisa ser sustentado por um paradigma e mais que isso, pela reversibilidade entre conhecimento ontopsicológico para o proceder de produção do conhecimento e pesquisa em todas as áreas do fazer humano. A Ontopsicologia dá o parâmetro para poder sustentar o valor da ciência, desta forma deve-se fazer a pesquisa usando ciência por ciência.
\end{abstract}

Palavras-chave: Ciência; Ontopsicologia; Pesquisa.

\section{Research on ontopsychology}

\begin{abstract}
The paper approaches ontopsychological research, in which it states that the entire research process to confirm itself as a science needs to be supported by a paradigm and more than that, by the reversibility between ontopsychological knowledge for the proceeding of knowledge production and research in all Areas of human doing. Ontopsychology gives the parameter to be able to sustain the value of science, in this way one must do the research using science by science.
\end{abstract}

Palavras-chave: Science; Ontopsychology; Search.

Resúmen: El texto aborda la investigación ontopsicológica, en el cual afirma que todo el proceso de investigación para confirmarse como ciencia necesita ser sostenido por un paradigma y más que eso, por la reversibilidad entre conocimiento ontopsicológico para el proceder de producción del conocimiento e investigación en todas las Las áreas del hacer humano. La Ontopsicología da el parámetro para poder sostener el valor de la ciencia, de esta forma se debe hacer la investigación usando ciencia por ciencia.

Palabras-clave: Ciencia; Ontopsicología; Búsqueda.

Existem três livros que são básicos para termos uma certa diretiva na pesquisa:

\section{Percepção Ontológica, Racionalidade Ontológica e Conhecimento Ontológico e}

\footnotetext{
${ }^{1}$ Conferência realizada na Faculdade Antonio Meneghetti na data de 10 de dezembro de 2016, no Auditório Principal da AMF, com a presença de alunos dos Cursos de Pós-Graduação Lato Sensu MBA Identidade Empresarial, alunos do Curso de Especialização Lato Sensu Gestão do Conhecimento e o Paradigma Ontopsicológico, alunos do Bacharelado em Ontopsicologia, professores e pesquisadores em Ontopsicologia, público e comunidade acadêmica em geral.

${ }^{2}$ Professor, Doutor na Faculdade Antonio Meneghetti.
} 
Consciência, de autoria do Acadêmico Professor Antonio Meneghetti. Esses três livros, depois, são retomados e colocados em "Da Consciência ao Ser" ${ }^{\text {"3 }}$. Existe a necessidade de entender isso para fazer-se a revisão crítica da racionalidade e a revisão crítica dos conhecimentos. A revisão crítica não significa destruir esses conhecimentos, mas compreende como desenvolver uma inteligência para poder discernir como usá-los.

Então, isto é muito importante, porquê? Porque enquanto estamos presos e dependentes da ciência e da cultura aprendida e citamos a Ontopsicologia para confirmá-la, nós procedemos adaptando a Ciência Ontopsicológica aos estereótipos que nos foram ensinados.

Onde fica a crítica da racionalidade e a crítica dos conhecimentos? Este parece ser o problema. É muito importante que todo o processo de pesquisa, para confirmar-se como ciência, seja sustentado por um paradigma comum. O paradigma não é o método. O paradigma ( $\pi \alpha \rho \alpha ́ \delta \varepsilon \imath \gamma \mu \alpha=$ demonstração) de pará o que está sob, por baixo, sustenta a demonstração, esse é o paradigma. Então, é um modelo que sustenta e elabora o trabalho científico.

O conhecimento científico apoia-se, pois, nesse modelo. O modelo tem quatro pontos de passagem, primeiro 1) a observação; 2) a hipótese explicativa da causa; 3) a experimentação para confirmar a causa e 4) o critério de confirmação, que, na ciência quantitativa, é a matemática e, na ciência qualitativa, é a exatidão do cientista.

Quando tratamos de observar os fenômenos, temos fenômenos que tocam a percepção sensorial, eles nos dão informações do que está constituído, do que está já estruturado, daquilo que quantitativamente é mensurável. Depois, temos outros fenômenos que nascem do interior do corpo, do interior do constituído. Este elemento que nasce do interior do constituído para encontrar a causa, mas não somente fazemos uma redução das amostras, precisamos de uma nova percepção que foi denominada, na Ontopsicologia, percepção de Campo Semântico.

Assim, temos, de um lado, a ciência do externo e, de outro lado, a ciência do interior, apoiada em fenômenos que tocam a sensorialidade da percepção e que tocam as variações organísmicas. Precisamos de uma percepção acrescida e aperfeiçoada, que é irradiada pela dinâmica da vida para poder ler a causalidade desses fenômenos - o fenômeno da paixão, o fenômeno da emoção, o fenômeno do sonho, etc.

\footnotetext{
3 “Muitas pessoas pensam que comprando aquele, já também substituem esse, mas, não é bem assim”. Professor Dr. Alécio Vidor enuncia esta frase, neste momento da Conferência, referindo-se ao livro "Da Consciência ao Ser" e aos demais três livros citados anteriormente.
} 
Temos dois níveis de percurso para fazer a ciência integral. O critério matemático, que sustenta a ciência quantitativa, que busca a causa externa; e o critério da exatidão mental do cientista, que sustenta a ciência da vida, que é qualitativa e que busca as causas subjetivas internas.

A palavra "método" - do grego metá hodós, hodós - é o caminho usado para chegar à ciência que é a meta. Temos, assim, um método que caminha na busca do externo, apoiado na percepção sensorial para evidenciar uma hipótese explicativa que unifica os fenômenos observados. É o caso de quando observamos o movimento da Terra, o movimento do sol, o movimento dos planetas, o movimento dos fenômenos celestes e chegamos a uma explicação unificada que os corpos atraem-se em proporção da massa - aqui, temos uma causa externa explicativa.

Quando nós nos voltamos para o interior do corpo humano para termos a evidência das informações organísmicas - essas informações organísmicas que são projetadas a partir das variáveis do nosso organismo, e da intenção psíquica, darei um exemplo sobre como eu estou elaborando uma forma de pesquisa dentro de todo esse caminho - para encontrar a causalidade interna e essa sempre corresponde a uma intenção que é lida pelo Campo Semântico, uma intenção que indica o modo como a atividade psíquica está se movendo para construir um objeto concreto. Necessariamente, aqui, entramos em uma situação de interdisciplinaridade, que foi o que o Acadêmico Professor Antonio Meneghetti disse que nos compete começar a elaborar.

A interdisciplinaridade busca integrar a unidade dos dois campos da ciência, para poder, em uma evolução externa tecnológica, ser colocada a serviço da vida e não como instrumento destrutivo de vida ou agressivo à vida. Desse modo, as causas internas e externas necessitam de um princípio que unifique a dualidade e este princípio é a forma inteligente do homem, porque a consciência é um ramo dessa inteligência: é a possibilidade de reflexo inteligente do homem que dá a possibilidade de construir a unidade científica. Por quê?

Porque a ciência será sempre a projeção da informação do ser vital humano, será sempre a sua projeção. A inteligência da natureza humana dotou o corpo de receptores perceptivos múltiplos, mas, os estímulos foram direcionados para o uso de alguns receptores e a atenção e os interesses concentraram-se nas exigências existenciais. Com isso, formou-se uma consciência restrita às percepções periféricas do corpo voltadas ao externo e parte da inteligência integral da vida manteve-se inconsciente e censurada, 
sendo que, para recuperar as informações endoviscerais do organismo todo, o recurso é a Ontoterapia.

A Ontoterapia é o tirocínio de autenticação pessoal e social, é um tirocínio permanente durante a existência, não é um fato de uma análise que um psicólogo apenas faz, é um trabalho de constante revisão.

Apresentados esses elementos - eu os reputo básicos: o paradigma e os demais pontos abordados aqui - já dissemos que, para uma pesquisa ontopsicológica, não basta assessorar a nossa cultura já existente com citações da Ontopsicologia, isto não é pesquisa ontopsicológica, por quê?

Porque a Ontopsicologia dá o fundamento para poder sustentar o valor da ciência. Assim sendo, temos que fazer uma pesquisa para encontrar esse fundamento unificado, usando ciência por ciência, para poder fazer o percurso de redução ao ponto fundamental, do qual se originam todos os critérios racionais.

Tomando, como exemplo, a medicina como ponto de referência, nós temos a observação do orgânico. A ordem orgânica é mantida mediante proporções presentes no corpo, que corpo já é munido de forma inerente por um conjunto de normas para ser mantido em sanidade. Assim, a medicina estabelece as medidas matemáticas das inúmeras proporções adequadas à saúde do corpo. Então, tem tanto de proteína, tanto de doçura, tanto de vitamina, tanto de gordura, tanto de sais minerais, tanto de pressão, tanto de ritmo do coração, são todas medidas matemáticas que, pela percepção sensorial, foram estabelecidas como regras inerentes ao corpo humano.

Assim, ocorre o conhecimento quantitativo proporcional áquilo que as regras já inerentes do corpo pré-estabelecem. Tudo que diverge dessas regras constata-se com uma certa anomalia. Quando nós queremos dar continuidade a essa pesquisa, nós apenas, no início, estamos evidenciando, pela percepção sensorial, que é o primeiro nível de percepção já constituído, mas e quem é o constituinte? Quem é o agente psíquico que estruturou essa forma no corpo, quem é o agente psíquico? Passamos da observação do orgânico para a observação psicossomática e apenas damos uma ampliação e uma continuidade entre a visão sensorial e a visão psicológica, começamos, pois, integrar uma ciência na outra.

Na psicossomática, a ordem depende do agente psíquico e examina-se as causas subjetivas e inconscientes. As estruturas latentes e a experimentação recorrem, agora, não mais ao critério matemático, mas ao critério de análise racional, que é o caso da Psicanálise, que é o caso da Psicologia Analítica, etc. 
Essa análise racional - porque, aqui, começa a entrar um aspecto de contribuição para Ontopsicologia, mas a percepção do Campo Semântico dá a possibilidade de evidenciar a causa interna e que nem sempre coincide com a análise racional feita pelos especialistas. Então, por isso é que o Campo Semântico dará o critério de discernimento para fazer a crítica da racionalidade e evidenciar que a racionalidade, que se apoiou em tal critério, e que no inconsciente encontra-se ofendido o impulso sexual, ou que, no inconsciente, estão apenas os arquétipos e que os arquétipos definem o que é normal e o que não é - isso, pelo Campo Semântico, pode-se ver que é um limite de compreensão da racionalidade.

A lógica não embasa um apoio que não entende o princípio organizador dessas estruturas, que é o monitor de deflexão, eles não poderiam dar a versão correta dos sonhos, dos símbolos daquilo que o organísmico revela. Assim sendo, passamos de uma visão psicanalítica para uma visão de percepção do Campo Semântico, para poder dar a correção e a revisão crítica da racionalidade que construiu uma explicação limitada e incompleta - em alguns casos até incorreta - mas que não necessariamente é sempre falsa, porque pode acontecer que o elemento latente seja sexual, pode acontecer que o elemento latente seja um arquétipo, mas isso tudo depende do critério da informação do segundo nível de percepção, que é a percepção do Campo Semântico.

Essa observação, que, no primeiro caso, foi orgânico, no segundo caso, foi psicossomático, agora é organísmico = organo-psíquico. A observação organísmica evidencia, pela percepção do Campo Semântico, a intencionalidade correta da atividade psíquica e a intencionalidade incorreta da atividade psíquica. Essa atividade incorreta, que é de uma intencionalidade, temos que encontrar um princípio que lhe dê a origem, que lhe dê a informação fundante da intencionalidade correta e, assim, passamos da exigência da psicoterapia para corrigir as formas da crítica racional para uma percepção de um fundamento que se evidencia por 15 características. Para, em continuidade, fazermos as passagens e darmos a continuidade da Medicina à Psicossomática, da Psicossomática à Psicoterapia e da Psicoterapia à Ontopsicologia.

Esta é uma pesquisa de Ontopsicologia, por quê? Porque a Ontopsicologia tem que dar continuidade de uma disciplina na outra, que até hoje foram construídas como compartimentos estanques e que, às vezes, impondo-se como parcela superior a todas as demais, sem considerar que uma precisa estar unida à outra para fazer uma continuidade de conhecimento que especifica a unidade da ciência. 
Por exemplo, há necessidade de uma revisão crítica dos conhecimentos adquiridos, dos critérios correntes em todos os modelos da Psicologia, de fazer um percurso para dar continuidade ao critério criteriante - que é o que fundamenta os demais critérios racionais e que dá a base para poder evidenciar o conhecimento que temos - a base de conhecimento que precisamos ter é que a consciência precisa estar em coincidência ao refletir a informação do intelecto e esse exercício é indispensável pelo instrumento da Psicoterapia. Por isso, sem a Psicoterapia, sem a autenticação pessoal e social, é impossível pretender fazer pesquisa em Ontopsicologia, porque a autenticação é o preâmbulo para poder evidenciar essa continuidade de um compartimento ao outro, da passagem de um compartimento ao outro, por exemplo, como integrar as áreas da energia, seria outro trabalho.

A energia física, a energia etérica, a energia semântica, a energia formal, darei uma pesquisa para esclarecer a ligação e a continuidade de uma na outra? Para, de novo, dar como fundamentação o princípio ontológico, para poder fazer o nexo ontológico que é a função da Ontopsicologia, poder restabelecer a continuidade de um compartimento científico no outro, para, depois, poder unificar no princípio gerador do conhecimento científico humano que é a irradiação da informação da vida humana.

E como fazer? Por exemplo, na Filosofia, precisaria revisar autor por autor, conhecer a história de vida, compreender os modos como ele foi estruturado em sua consciência para, na sequência, designar o que é opinião e poder ver o que é realmente Filosofia pura.

Dessa forma, o trabalho que existe nessa pesquisa é muito amplo, é muito grande, e eu não vejo a possibilidade de se supor que cada um já esteja suficientemente preparado para fazer. Eu, há quarenta anos, estudo, item por item, para poder esclarecerme e porque o Acadêmico Professor Antonio Meneghetti diz que a exigência da Ontopsicologia - que é a ciência interdisciplinar - é fazer a unificação das ciências, é a continuidade entre elas, para poder dar como fonte unitária de conhecimento científico a emanação do intelecto humano, que, na sua integridade, reflete nosso modo de ser específico ou da nossa vida.

$\mathrm{Na}$ medicina, existem muitos detalhes que se deve saber e, posteriormente, vê-se que a medicina usou todos os recursos da ação externa - da alimentação, hoje, está usando muitos recursos da respiração, que já é uma novidade acrescida e, com este uso de saber servir-se de um ar diversificado produzido pela terra para regeneração do organismo já é um passo em avante para poder servir-se de recursos da natureza 
substituídos por interferências químicas no corpo. Já é uma vantagem, já é um aspecto de ampliação da ciência e, quando começamos a observar isso, vemos que o Campo Semântico também se insere dentro do ar, que, quando dizemos "o ar é pesado", é porque há um fator de nível emotivo que está contaminando aquela realidade e que tem a sua origem na psicossomática, na atividade psíquica. Essa psicossomática vai evidenciar disfunções e alterações no corpo que passam por uma interferência que não é dada pela alimentação e que não é dada pela atmosfera respirada, mas que é dada pelo agente interno, que constrói uma distorção no corpo.

Temos aí: como da medicina entra-se na psicossomática e, depois, como precisamos da psicoterapia para poder corrigir a análise racional que é feita na psicanálise, nas demais correntes. Não corrigir, mas simplesmente amplificar os pontos de origem, que a atividade psíquica uma vez em seu endereço sendo desvirtuado pela consciência, constrói uma disfunção e uma alteração no corpo. Assim, por essa passagem esse redutor interno não pode ser fixo nos arquétipos e não pode ser fixo simplesmente num instinto - porque quem rege a função dos instintos é um redutor interno que se chama monitor de reflexão, que atua através de imagem fixa para poder construir alteração no corpo, para poder construir os complexos internos, as estruturas latentes que fazem a consciência pensar desviada da intencionalidade original da vida.

Sei que isso não é fácil, que isso é difícil, porque o nosso risco, hoje em dia, é o seguinte, se começamos a adaptar citações da Ontopsicologia para confirmar a nossa cultura, vamos reduzir a Ontopsicologia a um monitor de deflexão. Esse é o problema, porque uma grande ciência que traz uma fundamentação de valor para resgatar a dignidade da vida humana pode ser reduzida às estruturas que estão construindo os modelos de guerra entre os seres humanos e não o Humanismo.

Não sei se fui claro porque não é que tem que aceitar isso que eu disse, mas é aquilo que eu apresento devido a um contínuo trabalho de estudo nessa ciência e o Acadêmico Professor Antonio Meneghetti, quando se referia a ela, dizia pode ser que, daqui a cinquenta, cem anos, a humanidade entenda. É um esforço próprio de cada um para poder ver que a cultura vigente não está dando resultado e demonstrar que a vida floresce, frutifica, humaniza o homem em um convívio - que quando eu olho o comportamento dos pássaros, dos animais silvestres que não entraram em contato com o homem e que não foram subjugados a uma influência de semântica humana sobre eles, eles têm um comportamento preciso dentro da ordem instintiva, mas se vê que, por trás 
daquela ordem instintiva, se ela põe a inteligência que os guia sem que eles tenham consciência.

Nós recebemos uma consciência ou construímos uma consciência, primeiro, em processo de adaptação aos outros e nós temos que recuperar a informação que brota do íntimo da vida e isso é uma proposta da Ontopsicologia, quando usa o termo Em Si ôntico, significa sempre o nexo ontológico que nós temos que fazer reduzindo os vários compartimentos a uma unificação de saber que irradia a possibilidade de viver e conviver de modo humano.

Inicialmente, é preciso ver bem como são, como é a metodologia tradicional de pesquisa e até, inclusive, dentro dessa metodologia, começar a inserir uma crítica que possa resgatar uma passagem de conhecimento que essa metodologia fixa não permite, começar daquilo que está impedindo o avanço da compreensão humana, porque, pela metodologia vigente, a parte subjetiva humana é um tanto excluída, vamos dizer assim, se essa parte humana que é a que gera o conhecimento verdadeiro fica excluída, que valor tem esse conhecimento mediante a essa metodologia?

\section{Em resposta a uma pergunta feita por um dos presentes:}

Isto significa começar a fazer análise crítica, não análise crítica para condenar, mas para dizer: "bom, vocês nos deram um compartimento, nos permitam aumentar um novo compartimento". Começar pelo próprio modelo tradicional a inserir um novo instrumento que faça a ampliação desse modelo, que elucida um pouco o significado etimológico da metodologia, metá hodós. A possibilidade de o método ser direcionado ao externo e o método ser direcionado ao íntimo da subjetividade, vamos começar por aquilo que dá para fazer e começar a ver até quando os pesquisadores podem dar o contributo também de elucidação nova, daquilo que não foi feito até hoje, porque não dá para, simplesmente, pretender o máximo se não se fez as passagens no mínimo.

É todo um trabalho a ser feito. Comumente, se eu vou descrever todos os passos que se dá desde a medicina à psicossomática, da psicossomática à psicoterapia, da psicoterapia à Ontopsicologia, esses passos descrevem muitas partes, porque o primeiro trabalho da ciência é encontrar um redutor explicativo, que é a causa e a hipótese, e, depois, apoiar-se em um critério de valor para poder justificar essa hipótese, que é válida como causa. Depois, deve-se subordinar a uma experimentação que confirme as medidas da perfeição do cientista para poder validar. É sempre esse fato, eu, da parte da 
passagem da medicina para a psicologia, da medicina para a hipoxia, da hipóxia para à psicossomática, escrevi 15 páginas, mas isso é análise que se faz.

Novidade de ciência! Nós temos poucos recursos nos livros, porque nós estamos dando uma contribuição de novidade à ciência para aperfeiçoar o conhecimento da vida, e, nisso, os subsídios escritos são poucos, mas há certos lampejos também dentro da filosofia, porque se eu olhar Marx e disser que "Marx não se deve aceitar", isto é uma opinião contra a opinião dele, mas isso não significa ciência e nem significa filosofia. Nós temos que ver onde estão, porque Marx disse tantas coisas que são válidas, quando ele teve um momento de intuição e esses momentos de intuição são presentes em vários pensadores. Porque, por exemplo, quando Marx diz o seguinte: "não é a consciência do homem que define seu ser, mas, é o ser social que determina sua consciência" está correto, não tem nada modificado, porque ele já aponta onde está o caminho do erro, que é a consciência falsa, mas ele dá essa frase solta, dentro de outros elementos e, depois, centraliza tudo na economia. E economia é um bem para formar o corpo, o corpo do humano, o corpo de uma instituição, mas a economia não é a inteligência toda da vida humana, é uma parte. Como passar da economia para a mente? 